\title{
Experiência do Usuário para Geração Conceitual de Interface de um Aplicativo de Transporte Público Coletivo
}

\author{
User Experience for a Conceptual Interface Generation of a Public Transportation \\ Application
}

\author{
CARREIRO, Elioena Menezes; Graduanda em Design; UFMA \\ elioenacarreiro@gmail.com \\ NUNES, Isabella Priscila Pereira; Graduanda em Design; UFMA \\ Isabella.priscilap@gmail.com \\ DEMAISON, André Leonardo; Mestre em Design; UFMA \\ demaison@gmail.com
}

\section{Resumo}

Este artigo tem o intuito de apresentar uma proposta conceitual para a interface de um aplicativo para transporte público coletivo, o ônibus. Para chegar nos requisitos projetuais foram utilizadas técnicas voltadas à experiência do usuário, como o minigrupo de foco, o teste de usabilidade e a avaliação heurística, apresentadas em um estudo prévio. Para o desenvolvimento da interface apresentada aqui, foram utilizadas as técnicas do card sorting, a prototipagem em papel e o diagrama de arquitetura da informação. Para o sucesso de uma aplicação móvel que leve em conta o usuário, o designer estuda todos os erros e viabiliza acertos previamente para uma melhor experiência retratada no visual. $\mathrm{O}$ artigo traz o processo de desenvolvimento e o resultado dessa proposta, de maneira a melhorar a experiência do usuário na utilização do aplicativo.

Palavras Chave: experiência do usuário; interface do usuário; transporte público e aplicativo.

\begin{abstract}
This paper intends to present a conceptual interface proposal for a public transportation application, the bus. In order to meet the goals, user experience techniques such as the mini focus group, the usability test and heuristic evaluation were used, previously presented in another study. For the development of the interface, the techniques of card sorting, paper prototyping and information architecture diagram were used. For the success of an application, which takes into account the user, the designer studies all the errors and takes in consideration previous answers for a better experience portrayed in the visual. The paper brings the development process and the result of this proposal, in order to improve the user experience when using the application.
\end{abstract}

Keywords: first keyword; second keyword; third and last keyword. 


\section{Introdução}

A necessidade de facilitar determinadas tarefas no decorrer do dia a dia faz com que as pessoas recorram ao uso de aplicativos móveis, costume cada vez mais difundido a partir do crescente uso de smartphones. Tais aplicativos (também chamado de apps) procuram agilizar a realização dessas tarefas como: pedir um serviço de entrega delivery, um transporte ou até mesmo o aluguel de espaços. O mercado de aplicativos vem crescendo tanto que, de acordo com a $B I$ Intelligence, do site internacional de notícias Business Insider, no quarto semestre de 2017 já haviam 27 bilhões de downloads, sendo este um número $7 \%$ maior que o ano anterior.

Alguns dos aplicativos mais populares tratam do transporte tanto público quanto privado, no intuito de facilitar não só a informação sobre estes serviços, quanto até mesmo facilitar o acesso a eles. São aplicativos para táxis, aluguel de carros particulares e também para informações sobre o transporte público. O transporte público coletivo é o meio de locomoção público essencial declarado pela Constituição Federal de 1988, no inciso V do artigo 30, e utilizado pela maior parte da população das grandes cidades, como é o caso do ônibus. Devido a tal fator, surge o debate de trabalhar aplicativos móveis que ajudem a melhorar a experiência dos usuários dos ônibus.

O processo de design de uma interface para aplicativo móvel não se baseia somente no que é agradável visualmente, mas uma consequência de diversas técnicas cuidadosamente aplicadas para que o designer possa entender o usuário e assim projetar aplicações móveis que correspondam com a necessidade do mesmo.

Primeiramente, para se projetar leva-se em consideração o trabalho do User Experience Designer (UX), ou Designer da Experiência do Usuário, antes mesmo de considerar-se uma interface. A Experiência do Usuário é, segundo Norman (2008), a forma como a pessoa interage e sente com um produto. É através da experiência do usuário e de suas expectativas que se pode considerar um visual apropriado para a aplicação móvel. Antes de considerar as etapas do design de interface apresentadas aqui, foram previamente elaboradas as pesquisas a partir de um minigrupo de foco, de um teste de usabilidade e da análise heurística com especialistas, etapas estas apresentadas em um estudo anterior.

O minigrupo de foco consiste em um encontro com determinado número de usuários, com cinco a seis pessoas, com moderadores isentos da participação da discussão. Nesta etapa elaborouse um roteiro de perguntas, como: "quando e porque utilizam um aplicativo para transporte público coletivo?", "quais as vantagens deste tipo de aplicativo?", "quais as insatisfações com este aplicativo?" e "o que mudariam ou acrescentariam no aplicativo?". Para Edmunds (1999) este tipo de grupo propõe uma melhor interação devido à quantidade menor de participantes. A partir destas respostas, partiu-se para o teste de usabilidade.

Para Santa Rosa e Moraes (2012), aplicado tanto na área de ergonomia quanto na de interação humano-computador, no teste de usabilidade demonstra-se aplicativos similares ao que se está estudando, para que os usuários façam comparações. Ainda segundo um roteiro, analisa-se o tempo em que os mesmos executam as tarefas determinadas, como: buscar uma rua, buscar um ponto de ônibus e encontrar um terminal de ônibus. Também se analisou a lógica em que cada usuário utilizou para alcançar tais funções.

Partiu-se então para a avaliação das dez heurísticas com especialistas no assunto, conforme as recomendações de Nielsen (1994). Neste caso, o especialista descreve o local do problema de 
usabilidade, relata o problema, anota a heurística desobedecida e classifica o nível de criticidade.

Por fim, para que se pudesse projetar a interface descrita neste artigo, foram aplicadas três técnicas: o card sorting, a prototipagem em papel e o diagrama de arquitetura da informação.

No card sorting utilizam-se papéis em branco, onde palavras referentes ao aplicativo são escritas e onde o usuário deve organizar e separá-las conforme achar mais lógico. Ao final desta etapa pode-se classificar melhor cada função que, futuramente, poderá ser aplicada na interface.

A prototipagem em papel propõe a simulação da interface de forma básica e de baixo custo, para que o usuário que venha a utilizar do protótipo possa sentir e agir como se estivesse utilizando um celular real com uma interface teste, e assim, perceber a lógica da ação a qual o usuário chega a determinadas atividades. Sendo assim, nesta etapa define-se e refina-se a estrutura a qual o aplicativo deve ser estruturado.

A arquitetura de informação apresenta um organograma com a hierarquia das funções presentes no aplicativo. A partir desta organização, são categorizadas e disponibilizadas as informações de forma clara e simples. É a partir da arquitetura de informação que se define os wireframes, ou seja, o esqueleto do projeto final.

Os resultados propostos neste artigo foram cautelosamente analisados através de todo o processo descrito acima para a geração conceitual de um aplicativo para transporte público coletivo, que minimize erros e proponha uma boa experiência para o usuário.

\section{Experiência do Usuário}

A Experiência do Usuário vem sido largamente utilizada no que se refere à experiência de quem entra em contato com sistemas, aplicações e produtos que requerem execução, diminuindo a chance de erros e fadiga cognitiva.

Cunhado por Donald Norman (1998), o termo conceitua-se por "todos os aspectos das interações do usuário com o produto: como ele é percebido, apreendido e usado. Inclui facilidade de uso e, mais importante de tudo, as necessidades (do usuário) que o produto satisfaz", no livro "The Invisible Computer".

A ISO (International Organization for Standardization) 9241-210:2010 define o termo como "percepções e respostas de uma pessoa que sejam resultantes do uso e/ou da antecipação do uso de um produto, sistema e/ou serviço".

Como disciplina, é uma área que engloba diversas áreas como psicologia cognitiva, design gráfico e ciência da computação, tornando-se assim um assunto multidisciplinar. Este assunto engloba desde produtos físicos a produtos virtuais, como serviços e ambientes.

Os avanços tecnológicos têm levado em consideração o usuário e uma melhor experiência e qualidade. De acordo com González-Sánchez e Gil-Iranzo (2013), "é aconselhável conhecer o conjunto de usuários que fazem uso do produto, a fim de experimentar experiências e possíveis sensações durante o processo interativo". Afirmam ainda que diante de um mercado saturado e competitivo, a experiência é o que faz a diferença para assegurar o sucesso do produto.

Para uma boa experiência do usuário em contato com um produto, analisam-se as formas de interação por meio de técnicas de especialistas como Nielsen, Norman, Santa Rosa e Moraes, Cybis e outros, onde baseiam-se os estudos da experiência para posteriormente aplicação na 
interface conceitual que foi proposta neste estudo.

\subsection{Card Sorting}

O card sorting vem sendo utilizado como técnica para auxiliar os pesquisadores a entenderem melhor o que os usuários compreendem e pensam sobre conceitos. A área de IHC (Interação Humano-Computador), segundo Nielsen (1993), tem como principal objetivo a representação mental dos usuários e como estes usuários modelam este domínio. Já para Toub (2000, p.19), "o card sorting é uma técnica bem estabelecida nos campos da psicologia e da usabilidade, e é extremamente útil para avaliar hierarquias".

Santa Rosa e Moraes (2012) classificam os objetivos do card sorting como: identificar a terminologia que usuários compreendem mais facilmente; identificar os itens difíceis de classificar; identificar informações que possam pertencer a mais de um grupo; perceber como diferentes públicos-alvo categorizam o conteúdo e perceber como cada perfil de usuário pode acessar determinado conteúdo.

Cybis et al. (2007) explica que no estágio de planejamento os participantes devem classificar os itens escritos em cada papel. No estágio de arranjo, o mediador deve embaralhar os cartões para que cada usuário os receba em ordens diferentes e instruídos a classificar de acordo com seus critérios. No estágio de eliciação pede-se para que cada usuário explique o agrupamento dos cartões e consequentemente qual a lógica da organização, sendo esta etapa opcional.

\subsection{Prototipagem em Papel}

Segundo Santa Rosa e Moraes (2012), "a prototipagem em papel se constitui em um método rápido e econômico para projetar e testar interfaces". Ela também se tornou a ferramenta de prototipagem mais popular para o design de interfaces, por conta da necessidade de se fazer alterações rápidas no projeto. Nielsen (2005) cita ainda que sua vantagem é a de poder encontrar os principais problemas de usabilidade antes mesmo de se tornem muito custosos e difíceis de trabalhar.

Esta técnica é de baixo custo e rápida, o que proporciona diversas vantagens como recolhimento de dados de navegação, conteúdo, funcionalidade e layout, podendo facilmente fazer alterações e eliminar quaisquer ambiguidades. As desvantagens estão no fato de não ser possível reproduzir a sensação de ter um feedback no toque, ao rolar a página pela scrollbar, digitar algo etc. Para Szekely (1994) a prototipagem em papel permite que o controle excessivo de detalhes, maior participação da equipe de design além de permitir anotações imediatas de forma textual.

\subsection{Arquitetura de Informação}

A arquitetura da informação é conceituada pelo Instituto Asilomar para Arquitetura de Informação como o design estrutural de grupos de informações relacionadas ou à arte e à ciência de organizar e rotular websites, intranets, comunidades online e softwares, com o intuito de dar suporte à usabilidade e à facilidade de obtenção de informações. Segundo Reiss (2000), para que uma arquitetura da informação seja considerada boa, ela deve contribuir para a eficácia, eficiência e satisfação do usuário durante a utilização do sistema em questão, mas que vai muito além do que meros itens. Esta técnica permite que se estruture e organize num organograma as funções e etapas necessárias para se chegar a determinada atividade no aplicativo e entender como as telas se interligam, facilitando assim o desenvolvimento de wireframes e conexões entre o usuário e app. 


\section{Design e Interface do Usuário}

A Interação Humano Computador (IHC) é a área que estuda a conexão entre o usuário, máquina e interface. A interface pode ser conceituada como o meio que interliga o usuário e o sistema. A interface entre usuários e sistemas computacionais diferencia-se das interfaces de máquinas convencionais por exigir dos usuários um maior esforço cognitivo em atividades de interpretação e expressão das informações que o sistema processa (Dix et al., 2003).

O design de interface é o estudo que visa o desenvolvimento e planejamento de interfaces de modo a melhorar a experiência do usuário e evitar erros. "A interface do usuário é o que permite que as informações sejam transmitidas entre um usuário humano e os componentes de hardware ou software de um sistema de computador." (IEEE, Std 610.12-1990)

Ao considerar-se o contexto de interface, é imprescindível que se fale sobre usabilidade. A ISO 9241-11 define usabilidade como "medida na qual um produto ser usado por usuários específicos para alcançar objetivos específicos com eficácia, eficiência e satisfação em um contexto específico de uso".

Os princípios para uma boa interface do usuário seguem as diretrizes do design gráfico, onde deve-se levar em consideração hierarquia, alinhamento, simetria, equilíbrio, tamanho, forma, posição, entre outros. Porém, muito além disto, segundo Foley et al. (1995) também se leva em consideração a agilidade do usuário e seu aprendizado no uso e a redução da taxa de erro, sendo estes fatores essenciais e cruciais para a usabilidade.

Deve-se levar em consideração ainda questões culturais de ícones e cores para que o resultado almejado sirva para qualquer usuário, independentemente de sua cultura e princípios, tornando-se assim uma responsabilidade mundial desejada. As cores no contexto da interface norteiam o usuário e servem de codificação e percepção das informações presentes.

Alguns termos são utilizados e aplicados para identificação nos resultados, como menu (opções listadas em conjunto, onde o usuário escolhe a ação e local desejado), home (tela inicial) e ícone (representação visual de um elemento).

\subsection{Smartphones e Aplicativos Móveis}

O uso de smartphones vem se tornando item utilitário e essencial para uma comunicação mais rápida entre as pessoas. De acordo com dados de uma pesquisa pela 28a Pesquisa Anual de Administração e Uso de Tecnologia da Informação nas Empresas, realizada pela Fundação Getúlio Vargas de São Paulo (FGV-SP), estimou-se que o Brasil possuía, em dados de final de 2017, um aparelho smartphone por habitante. Esta pesquisa levou em consideração apenas os aparelhos em uso. A MMA Mobile Report Brasil, em 2017, fez uma pesquisa com 804 participantes e obteve em seus resultados que $83 \%$ dos usuários baixam novos aplicativos devido à praticidade e $79 \%$ destes fazem download por serem gratuitos.

A crescente difusão destes aparelhos propulsiona a criação de aplicativos móveis. Os smartphones e seus diversos modelos possuem ainda variados tamanhos de tela, fator este que desafia o designer na criação e adaptação para que as informações não sejam comprometidas durante o uso dos aplicativos. A variedade de modelos, sistemas, tamanhos e fabricantes exigem dos designers e desenvolvedores bastante cuidado na geração destes apps, já que a usabilidade e experiência de uso pode mudar consideravelmente de um aparelho para outro. 


\section{Métodos e Técnicas}

Este artigo segue a metodologia proposta por alguns especialistas como Cybis, Santa Rosa e Moraes e Nielsen para o desenvolvimento de interfaces. Foram utilizadas três técnicas para a proposta desse aplicativo, sendo elas o card sorting (onde permite-se que o usuário livremente categorize um palavras em grupos que remetem a uma lógica), a prototipagem em papel (onde o usuário simula a utilização de um celular com a interface desenhada em um papel) e a construção do diagrama de arquitetura da informação (onde as informações recolhidas são ordenadas num organograma para que seja facilmente identificado a estrutura e a hierarquia das funções necessárias para o aplicativo). A partir dessas técnicas foi possível propor uma nova interface adequada ao uso em smartphones.

\section{- Card Sorting}

A técnica de card sorting consistiu-se na entrega aos participantes de cartões em branco que mostram o conteúdo do aplicativo em forma de palavras, sem que estejam agrupados. A partir daí os participantes devem fazer arranjos da forma que acharem mais adequados ao conteúdo. Quatro voluntários participaram dessa técnica.

Os objetivos alcançados nesta etapa permitem entender como o usuário pode vir a acessar certo conteúdo. $O$ resultado desta técnica permitiu categorizar melhor o fluxo ao qual os usuários tendem a agrupar as possíveis opções presentes no aplicativo.

Figura 1 - Card Sorting

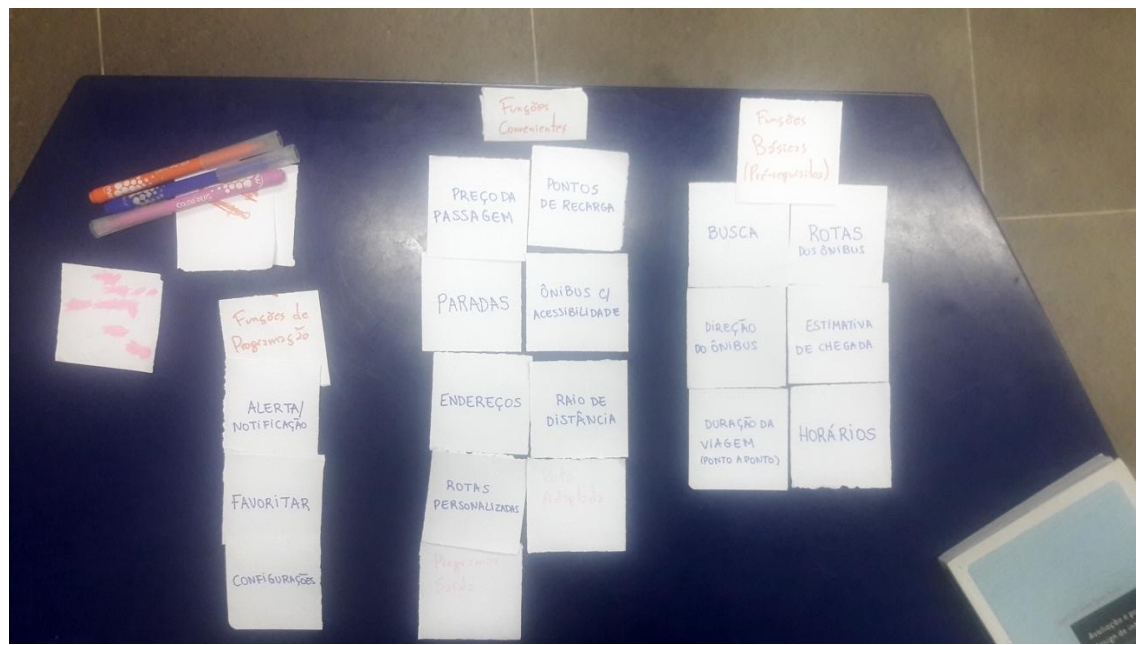

Fonte: Autores (2017)

\section{- Prototipagem em Papel}

Antes da elaboração do protótipo foram discutidas quais funções deveriam ser acrescentadas, baseadas na lista de requisitos elaborada na primeira etapa do projeto. Para o protótipo foi utilizada uma imagem impressa de um modelo comum de smartphone, que foi colado em um papelão, e as diferentes telas foram desenhadas à mão livre. Foi solicitado que os quatro usuários que utilizam esse tipo de smartphone testasse o protótipo. Foram atribuídas as seguintes tarefas: 
- Clique em uma parada próxima a você.

- Busque uma rota de ônibus.

- Favorite um ônibus.

- Configure o raio de alcance.

- Veja sua lista de favoritos.

- Configure as notificações do aplicativo.

- Volte para a página inicial.

- Busque uma rota de uma linha de ônibus.

- Busque um endereço para ver as paradas próximas.

Enquanto o protótipo era utilizado, as "telas" do aplicativo eram mudadas manualmente, para simular o uso no smartphone. Os usuários tiveram êxito em cumprir todas as tarefas.

Figura 2 - Prototipagem de papel
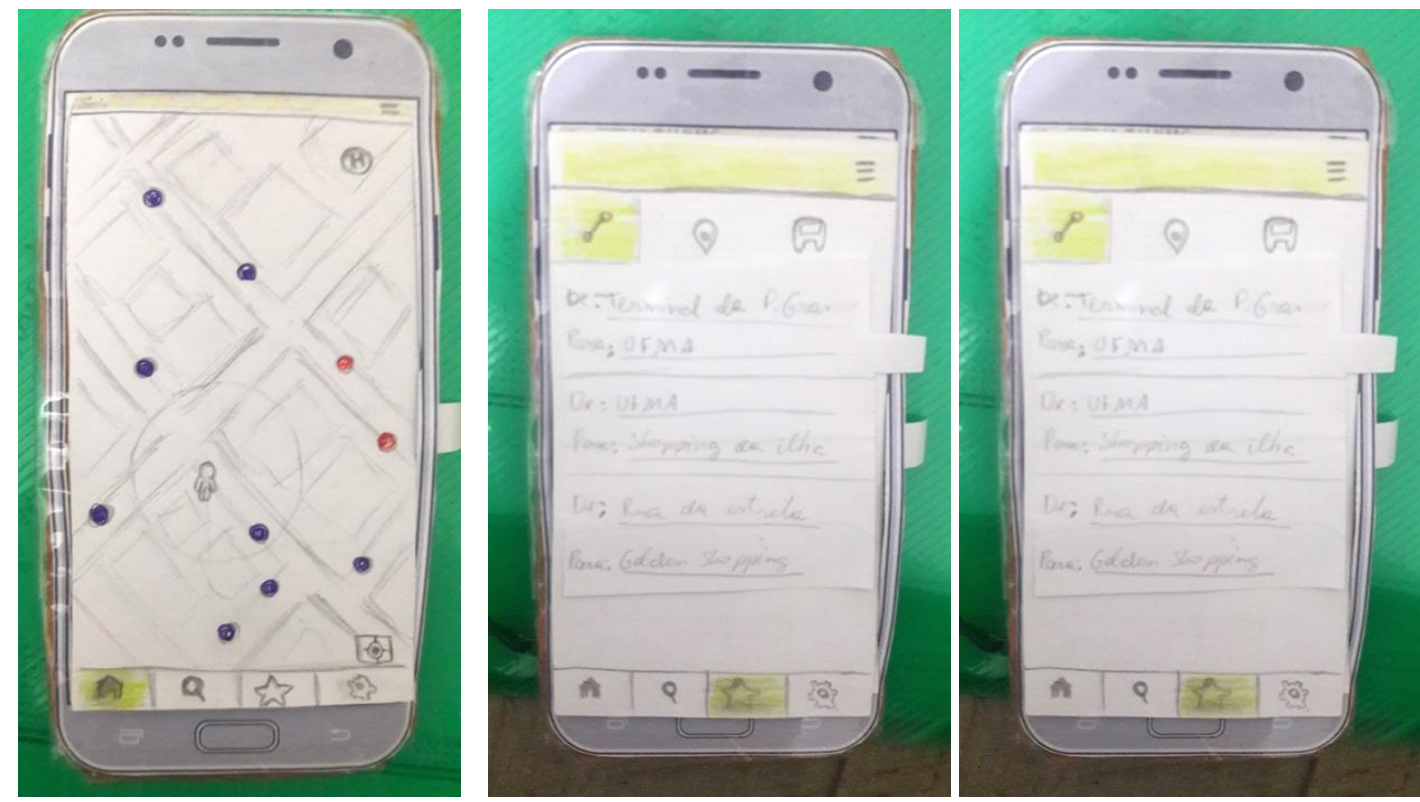

Fonte: Autores (2017)

\section{- Arquitetura da Informação}

Sendo assim, em seguida, utilizou-se desta técnica para a organização das funções do aplicativo já definidas nas etapas anteriores, para que sustentasse as informações de forma a serem alcançadas e de fácil acesso logicamente.

A arquitetura da informação permitiu organizar as informações em um organograma com a lógica de interação já previamente percebida através das técnicas anteriores.

Por meio desse organograma mapeiam-se as telas nas quais o aplicativo vai possuir interação, assim como o ligamento entre elas. Na figura 3 define-se esta estrutura. 
Figura 3 - Organograma da Arquitetura da Informação

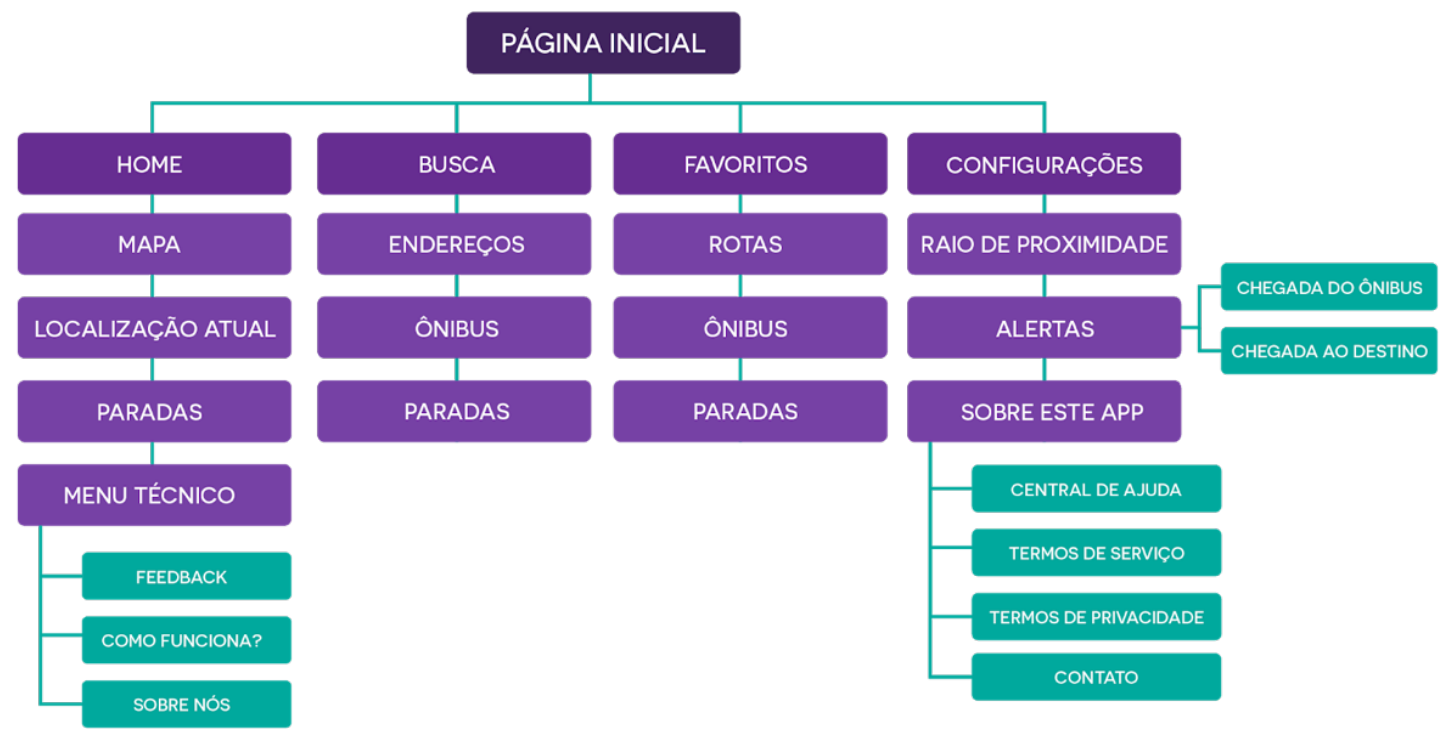

Fonte: Autores (2017)

\section{Resultados}

As propostas de alteração foram elaboradas a partir das primeiras etapas de conhecimento e da análise do aplicativo junto a usuários e profissionais especialistas em Ergonomia Informacional. Com os requisitos de melhorias em mãos, foram adicionadas às primeiras telas informações essenciais e claras para o usuário, assim como mensagens de alerta e feedback, seguindo um padrão de visual contrastante (figura 4).

Figura 4 - Tela Inicial e Feedback
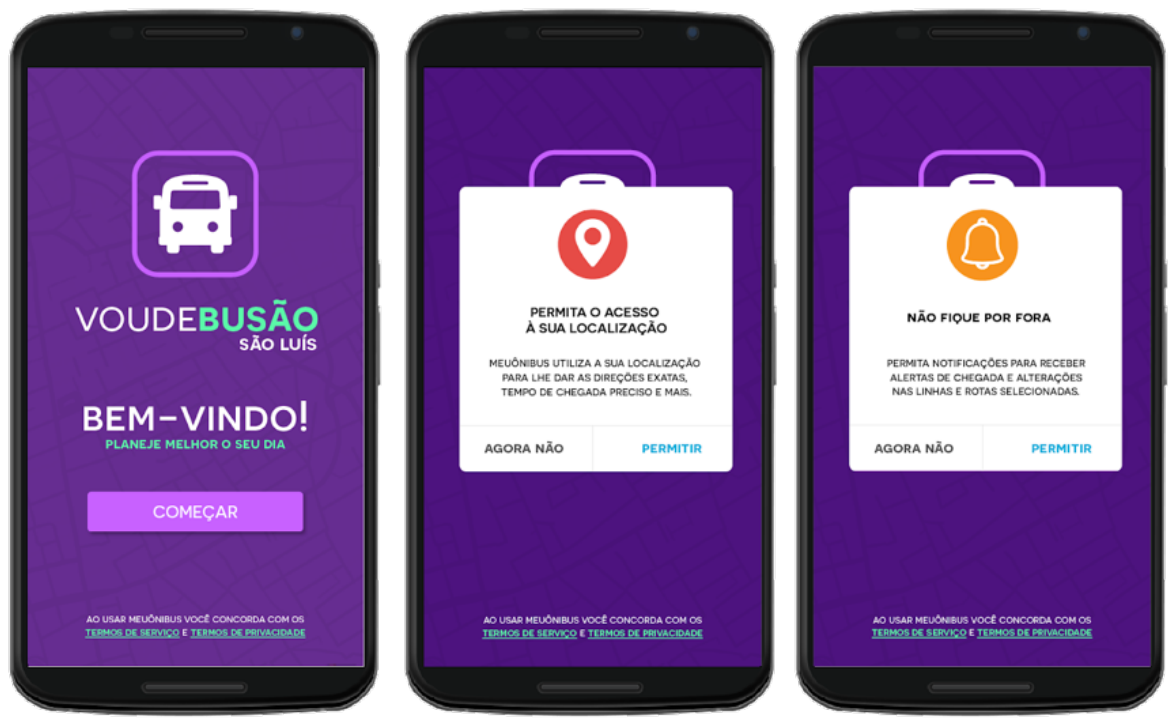

Fonte: Autores (2017) 
Em seguida, o menu inicial "home" (figura 5) permite o usuário checar sua localização e os ônibus que estão passando ao redor, assim como clicar neles, visualizar a rota, preço, se é um ônibus favorito e se possui acesso para portadores de necessidades especiais, neste caso, cadeirantes. Também é possível clicar no botão "menu" para mais funções como dar feedback no aplicativo, acessar as instruções de como o aplicativo funciona e saber mais sobre quem desenvolveu o aplicativo.

Figura 5 - Tela Home
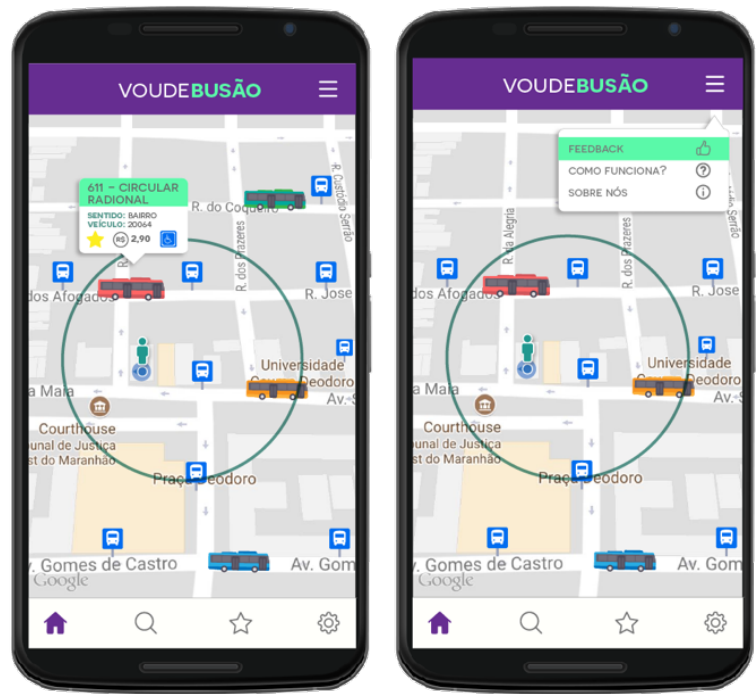

Fonte: Autores (2017)

Ao clicar no ônibus desejado, o usuário é direcionado para a tela onde constam as próximas paradas (figura 6), tempo estimado de chegada assim como acionar o alerta para descer caso a parada esteja próxima.

Figura 6 - Tela Home 2
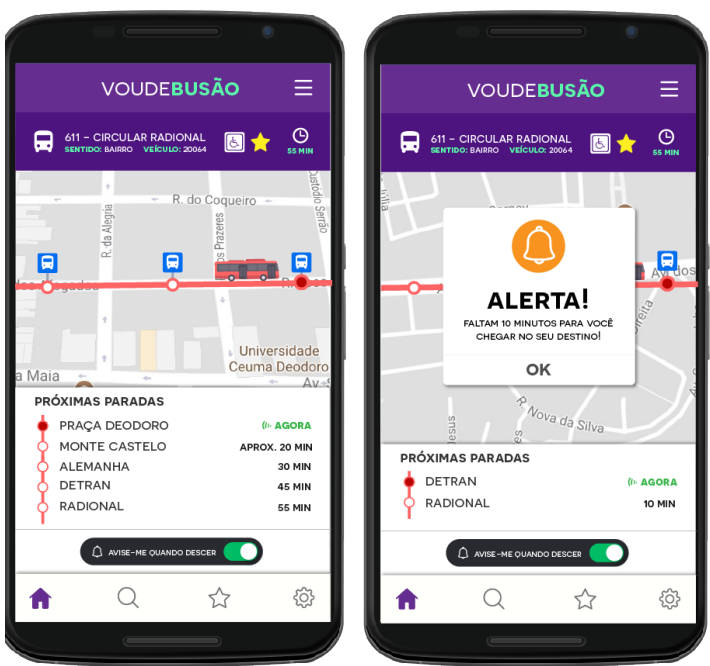

Fonte: Autores (2017) 
Na tela de busca (figura 7), pode-se ter três opções de atividades, funções estas que permite o usuário localizar um ônibus por meio de: local onde está no momento e local de destino que pretende chegar, localizar um ônibus pelo seu nome em específico e sua linha, assim como buscar o ônibus por sua parada. É possível também favoritar uma rota, um ônibus e uma parada. Estas informações são armazenadas nas telas com o símbolo estrela (figura 8).

Figura 7-Tela de busca
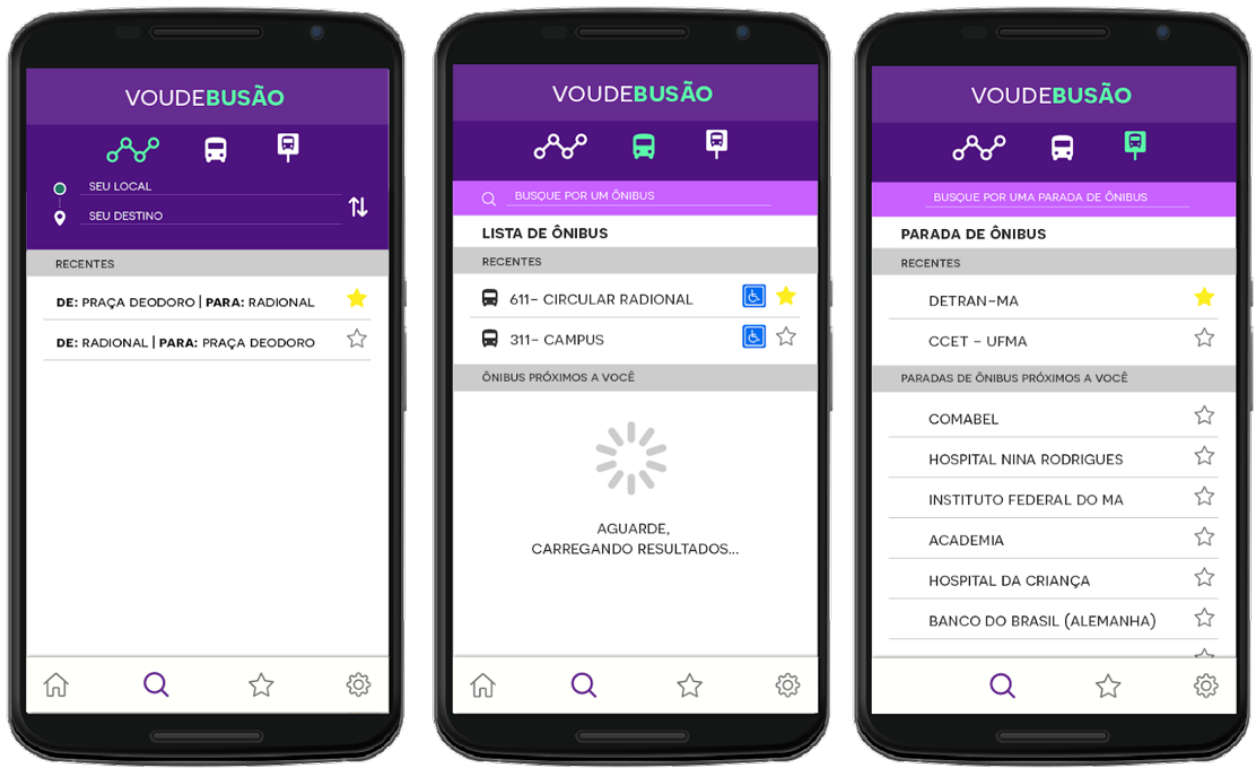

Fonte: Autores (2017)

Figura 8 - Tela de favoritos
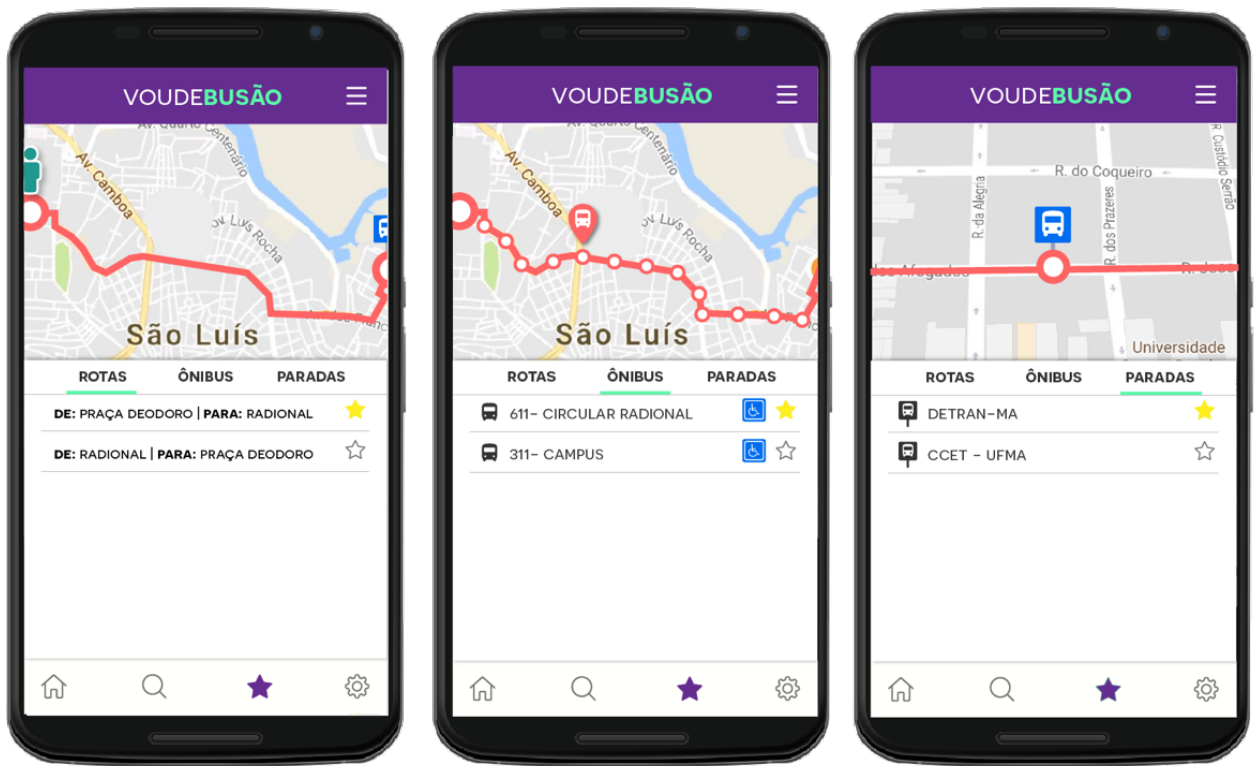

Fonte: Autores (2017) 
Por fim, a tela de configurações (figura 9) permitem o usuário a filtrar e limitar o campo de raio de distância dos ônibus a qual pretende-se alcançar, assim como, editar o alarme com o tempo previamente desejado. Informações sobre o aplicativo, central de ajuda, termos de serviço, termos de privacidade e contato também são opções disponíveis nesta tela.

Figura 9 - Tela de configurações

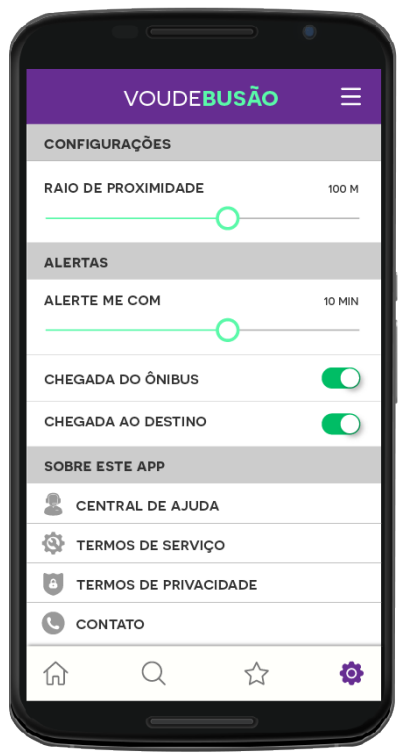

Fonte: Autores (2017)

\section{Considerações Finais}

Com base nas informações recolhidas nas etapas de testes da experiência do usuário, foi elaborada uma lista de requisitos para a etapa projetual da geração conceitual da interface do aplicativo. Consta no briefing questões como a revisão do ícone dos pontos de ônibus, do ícone dos ônibus, melhoria no campo de busca de endereço e criação da função "favoritar". Era previsto também criar uma mecânica de pesquisa de ônibus e suas rotas, uma nova configuração de mapa (atualmente é usado o do google maps), mensagens de feedback do aplicativo com o usuário e, por fim, adicionar sistema de notificação de aproximação do ônibus e de atualização automática da lista de ônibus.

Após colhidas estas informações por usuários que utilizam aplicativos de transporte público coletivo, deu-se a aplicação de etapas que permitiram a elaboração da geração de uma interface conceitual para o aplicativo em questão. Através do card sorting, prototipagem em papel e arquitetura da informação, levantou-se dados essenciais para a estruturação do aplicativo.

No resultado final da proposta constam todos os requisitos desejados que permitem ao usuário facilmente assimilar as funções a qual o aplicativo possui. A partir da proposta conceitual gerada foi possível ter uma visão mais clara de como as funções deste aplicativo funcionariam. 0 protótipo virtual foi cautelosamente desenvolvido para que englobasse todas as funções especificadas nas necessidades do usuário que utiliza o transporte público coletivo com frequência, eliminando erros de aplicativos similares e propondo um novo tipo de interação entre usuário e interface. 


\section{Referências}

BARBOSA, Simone; SILVA, Bruno. Interação humano-computador. Elsevier Brasil, 2010.

BRASIL. Constituição (1988). Constituição da República Federativa do Brasil. Brasília, DF: Senado Federal: Centro Gráfico, 1988. 292 p.

CANAL TECH. Mercado de Aplicativos Bate Recorde de Downloads e Receita no Fim de 2017. Disponível em: <https://canaltech.com.br/mercado/mercado-de-aplicativos-bate-recorde-dedownloads-e-receita-no-fim-de-2017-107384/> Acesso em: 20 de março de 2018

CAPELAS, Bruno. Até o fim de 2017, Brasil terá um smartphone por habitante, diz FGV. Disponível em: <http://link.estadao.com.br/noticias/gadget, ate-o-fim-de-2017-brasil-tera-um-smartphonepor-habitante-diz-pesquisa-da-fgv,70001744407> Acesso em: 20 de março de 2018

CYBIS, W.; BETIOL, A. H.; FAUST, R. Ergonomia e usabilidade: conhecimentos, métodos e aplicações. 2. ed. São Paulo: Novatec Editora, 2010.

DIX, Alan. Human-computer interaction. In: Encyclopedia of database systems. Springer US, 2009. p. 1327-1331.

FALAVIGNA, Vinícius Deboni. Experiência do usuário: análise e aplicação de métodos de avaliação. 2015.

FEIJÓ, Valéria Casaroto; GONÇALVES, Berenice Santos; GOMEZ, Luiz Salomão Ribas. Heurística para avaliação de usabilidade em interfaces de aplicativos smartphones: Utilidade, produtividade e imersão. Design \& Tecnologia, v. 3, n. 06, p. 33-42, 2013.

GONZÁLEZ-SÁNCHEZ, José-Luis; GIL-IRANZO, Rosa-María. FACTORES HEDÓNICOS Y MULTICULTURALES QUE MEJORAN LA EXPERIENCIA DE USUARIO EN EL DISEÑO DE PRODUCTOS. EI profesional de la información, v. 22, n. 1, 2013.

GUIDINI, P. A. A comunicação com o mercado por meio de aplicativos: desafios e oportunidades. Signos do Consumo, São Paulo, v. 10, n. 1, p. 59-69, jan./jun. 2018.

HUGHES, John F.; FOLEY, James D. Computer graphics: principles and practice. Pearson Education, 2014.

IEEE STANDARDS COORDINATING COMMITTEE et al. IEEE Standard Glossary of Software Engineering Terminology (IEEE Std 610.12-1990). Los Alamitos. CA: IEEE Computer Society, v. 169, 1990.

INSTITUTO ASILOMAR. Definindo Arquitetura de Informação. Disponível em: < http://archive.iainstitute.org/pt/sobre_aifia.html> Acesso em: 20 de março de 2018

ISO, W. 9241-11. Ergonomic requirements for office work with visual display terminals (VDTs). The international organization for standardization, v. 45, p. 9, 1998.

LOPES, ELISABETE CRISTINA. Uma (re) visão do conceito de experiência do usuário: a experiência como narrativa. Especialização em Comunicação Digital. Escola de Comunicações e Artes. São Paulo: USP, 2012.

NORMAN, Donald A. The invisible computer: why good products can fail, the personal computer is so complex, and information appliances are the solution. MIT press, 1998. 
PADOVANI, Stephania; RIBEIRO, Murilo Amgarten. Card Sorting: adaptação da técnica para aplicação ao design de sistemas de informação não digitais. InfoDesign-Revista Brasileira de Design da Informação, v. 10, n. 3, p. 293-312, 2013.

REISS, Eric L. Practical information architecture: a hands-on approach to structuring successful websites. Pearson Education, 2000.

SANTA ROSA, J. G.; MORAES, A. 2008. Avaliação e projeto no design de interfaces. Teresópolis, $2 A B$ SANTA ROSA, José Guilherme; MORAES, Anamaria de. Design participativo, técnicas para inclusão de usuários no processo de ergodesign de interfaces. Rio Book's, Rio de Janeiro, 2012.

STANDARDIZATION, I. O. F. Ergonomics of human-system interaction: Part 210: Human-centered design for interactive systems. 2010.

SZEKELY, Pedro. User interface prototyping: Tools and techniques. In: Workshop on Software Engineering and Human-Computer Interaction. Springer, Berlin, Heidelberg, 1994. p. 76-92.

TOUB, Steve. Evaluating information architecture: a practical guide to assessing web site organization. Argus Center for Information Architecture, 2000. 